Vol.59: e16160392, January-December 2016 http://dx.doi.org/10.1590/1678-4324-2016160392 ISSN 1678-4324 Online Edition
BRAZILIAN ARCHIVES OF BIOLOGY AND TECHNOLOGY

AN INTERNATIONAL JOURNAL

\title{
Effects of Arbuscular Mycorrhiza on Osmotic Adjustment and Photosynthetic Physiology of Maize Seedlings in Black Soils Region of Northeast China
}

\author{
Hongwen $\mathrm{Xu}^{1}$, Yan $\mathrm{Lu}^{1 *}$, Xiancan $\mathrm{Zhu^{2 }}$. \\ ${ }^{1}$ Huaiyin Normal University, Huai'an, China; ${ }^{2}$ Northeast Institute of Geography and Agroecology Chinese, \\ Academy of Sciences, Changchun, Jilin, China.
}

\begin{abstract}
To investigate the effect of arbuscular mycorrhiza fungi on maize growth, osmoregulation substances and photosynthetic physiology, a popular maize variety ZD 958 was measured under potted condition. Arbuscular mycorrhiza (AM) symbiosis promoted plant growth, and enhanced plant height, leaf length, mean leaf width and dry weight. Higher soluble sugar and protein, but lower proline concentrations were detected in AM seedlings than corresponding non-AM seedlings. Quantum yield of PSII photochemistry and potential photochemical efficiency increased by arbuscular mycorrhiza fungi, meanwhile, AM plants had lower primary fluorescence but higher maximal fluorescence and variable fluorescence than non-AM plants. AM enhanced apparent quantum efficiency, maximum net photosynthetic rate, dark respiration rate and light saturation point, but reduced light compensation point. The conclusion was that, after the seedling inoculated with Glomus. tortuosum, AM symbioses could protect cell from being hurt through regulating substances related to osmotic adjustment, besides, the efficiency of light utilization, the capacity of using low light and the capacity of fitting and using high light were all increased by AM symbiosis.
\end{abstract}

Key words: arbuscular mycorrhiza, maize, osmotic adjustment, light response curve

\footnotetext{
*Author for correspondence: yanyan0451_0451@163.com
} 


\section{INTRODUCTION}

Arbuscular mycorrhiza fungi (AMF) is a kind of important soil fungi which can shape mutualistic symbiotic relationships with a majority of terrestrial plants ${ }^{1,2}$, and it represents the oldest and most widespread symbiosis with land plants. Plant performance can be elevated by AMF under different condition by means of utilizing various mechanisms ${ }^{3}$. Many researchers reported that AMF could improve rhizospheric and soil conditions, and assist plants to obtain various nutrient elements from soil environment, moreover, AMF may accelerate nutrition absorption and transfer, particularly phosphorus ${ }^{4-6}$. And the extraradical mycelium can also give rise to organic components accumulation by delivering stimulating substances to the soil ${ }^{7,8}$. It is described that AMF could increase output of protective enzymes and hormones throughout the entire plant as well ${ }^{9-11}$. Also, it's well known that AMF can help to regulate accumulation of osmoregulation substances ${ }^{12,13}$ and enhance photosynthetic capacity and water use efficiency ${ }^{14,15}$. Thus, it has been widely accepted that arbuscular mycorrhiza (AM) symbiosis play an important part in plant nutrition and soil fertility, and it may be of great benefit which include increased nutrient uptake, productivity, and improved yield quality to many crops grown around the world.

Osmotic adjustment is considered compatible with growth and yield because it aid in the maintenance of leaf turgor, and many kinds of organic solutes are formed in the process of osmotic adjustment for the sake of keeping osmotic balance ${ }^{16}$. These organic solutes can alleviate the inhibitory effects on enzymatic activity under stress conditions, moreover, they may act as antioxidants in scavenging free radicals, protect specific biomacromolecules and stabilize membrane structures ${ }^{17,18}$. Soluble sugar, which contributes more to osmotic adjustment, and soluble protein is not only important to osmotic adjustment substance but also nutritive material under environmental stress, which can improve water retention ability in plant cells. Thus, soluble sugar and protein play important role in osmoregulation when plants inoculated with $\mathrm{AMF}^{19,20}$. Proline accumulation is often one of the research targets when many plants exposed to negative environment ${ }^{21}$, it plays multiple role during the procedure of osmotic adjustment as a sort of particular physiological reactions related to detection of various environmental stresses ${ }^{22-24}$. Porcel and Ruiz-Lozano ${ }^{25}$ reported that AM plants accumulated much more osmotic adjustment substances than non-AM ones, but conflicting changes were also found in other's publications. Thus, the influence of AMF on osmotic adjustment mechanism remains to be further explored ${ }^{26}$.

Photosynthesis is the physico-chemical process by which green plant and certain other organisms use solar energy to drive the synthesis of organic compounds, and it can provide the basic energy source for virtually all organisms. Plant photosynthesis is sensitive to light intensity, too low light intensity will affect carbonization ability, meanwhile, too high light intensity may easily hurt plant. Light saturation point and light compensation point can reflect the requirement of solar condition for plant. Light can influence photosynthesis in three aspects, to begin with, light supply energy for assimilation force. Furthermore, light can activate key enzymes to photosynthesis and promote stomatal opening. Besides, light may regulate the development of photosynthetic apparatus. Plant photosynthetic light-response curve may describe the relationship between photosynthetic photon flux density and net photosynthetic rate, besides, light compensation point, light saturation point, apparent quantum efficiency (AQE), maximum net photosynthetic rate (Amax) and dark respiratory rate $(\mathrm{Rd})$ can be detected by means of photosynthetic light response curve, and which can provide basement for study on the process of plant physio-ecology. Photosynthesis may be affected by both biotic and abiotic factors. So far, substantial publications were focused on the effect of soil compaction ${ }^{27}$, drought $^{28,29}$, temperature ${ }^{30}$, salinity ${ }^{31}$, nitrogen ${ }^{32}$ and phosphorus nutrition ${ }^{33}$ on the photosynthesis of maize, just few publications reported microorganisms and even no report on the effect of AMF on light response curve of maize leaves. Main purpose of our study contains three major components: (i) to analyze the effects of $\mathrm{AM}$ on maize growth; (ii) to reveal the changing mechanism of substances related to osmotic adjustment after inoculation with AM; (iii) to make clear the relationships between AM and photosynthetic characters of maize seedlings. 
Effects of mycorrhizal on osmotic adjustment

\section{MATERIALS AND METHODS}

\section{Experimental materials and growth conditions} Seeds of the maize cultivar ZD 958 were disinfected using 70 percent of ethanol for $1 \mathrm{~min}$, then were treated in 0.5 percent of $\mathrm{NaClO}$ for 20 min, washed 4 times in sterile water. Finally, seeds germinated on moist filter paper in culture dishes at $28^{\circ} \mathrm{C}$ for couple days. Experimental soil took from Dehui Agricultural Experimental Station of Jinlin province, China, soil physic-chemical properties were given in Tab. 1 .

Tab. 1. Black soil physico-chemical profile

\begin{tabular}{lllllllll}
\hline Parameter & $\begin{array}{l}\text { Organic matter } \\
(\mathrm{g} / \mathrm{kg})\end{array}$ & $\begin{array}{l}\text { Total N } \\
(\mathrm{g} / \mathrm{kg})\end{array}$ & $\begin{array}{l}\text { TotalP } \\
(\mathrm{g} / \mathrm{kg})\end{array}$ & $\begin{array}{l}\text { TotalK } \\
(\mathrm{g} / \mathrm{kg})\end{array}$ & $\begin{array}{l}\text { Avail. N } \\
(\mathrm{mg} / \mathrm{kg})\end{array}$ & $\begin{array}{l}\text { Avail. P } \\
(\mathrm{mg} / \mathrm{kg})\end{array}$ & $\begin{array}{l}\text { Avail. K } \\
(\mathrm{mg} / \mathrm{kg})\end{array}$ & $\mathrm{pH}$ \\
\hline Mean & 26.9 & 1.20 & 1.06 & 16.87 & 111.80 & 18.00 & 111.00 & 6.80 \\
\hline
\end{tabular}

\section{AM Fungi Inoculum}

The AM fungi inoculum, Glomus. tortuosum, was purchased from the Institute of Plant Nutrition and Resources, Beijing Academy of Agriculture and Forestry Sciences, China. The inoculum comprised spores with density of 1,000 every $10 \mathrm{~mL}$ inoculum. $20 \mathrm{~g}$ inoculums were placed in each pot as AM treatment, and application of same quality of sterilized inoculums as non-AMF treatment.

\section{Experimental design}

The experiment was designed with five replicates with Glomus. tortuosum and non-AMF control. 3 pre-germinated seeds were planted in each pot consisting of $2.0 \mathrm{~kg}$ sterilized mixture of black soil and sand $(1: 1.5, \mathrm{v} / \mathrm{v})^{34}$. The seedlings were thinned to 2 seedlings each pot after emergence. The maize seedlings grew for 5 weeks under controlled greenhouse environment with $14 \mathrm{~h}$ daylengths and approximately $80 \%$ relative humidity. Each pot was weighed and irrigated with sufficient water to avoid soil water deficits, and the plants were fertilized with $100 \mathrm{~mL}$ Hoagland's nutrient solution weekly to prevent nutrient deficiency.

\section{Measurement}

After maize grew for 7 weeks, plant height, leaf length and mean leaf width were recorded by flexible rule. The shoot and root systems were parted, and their dry weights were measured after oven-drying at $75^{\circ} \mathrm{C}$ for 2 days ${ }^{35}$.

Soluble sugar and proline estimations were performed following the procedures that were described by Zhang and $\mathrm{Qu}^{36}$. Soluble protein content was determined by the methods of Bradford $^{37}$.

Chl fluorescence was tested with OS-30P type of portable Chl fluorometer made from Inc., USA. After dark adaption for half an hour, primary fluorescence $\left(\mathrm{F}_{\mathrm{o}}\right)$, maximal fluorescence $\left(\mathrm{F}_{\mathrm{m}}\right)$, Quantum yield of PSII photochemistry $\left(\mathrm{F}_{\mathrm{v}} / \mathrm{F}_{\mathrm{m}}\right)$ of maize were taken notes after $3 \mathrm{~s}$ saturating pulse at $3000 \mu \mathrm{mol} \cdot \mathrm{m}^{-2} \cdot \mathrm{s}^{-1}$ radiation level, whereafter, variable fluorescence $\left(\mathrm{F}_{\mathrm{v}}\right)$ and potential photochemical efficiency $\left(\mathrm{F}_{\mathrm{v}} / \mathrm{F}_{\mathrm{o}}\right)$ were obtained ${ }^{13}$.

Photosynthetic light-response curves were measured through portable photosynthesis system LI-6400 (Li-cor Inc., USA). For maize leaves, 10 min retention in the chamber was needed in order to be in equilibrium. Measurements were taken at irradiance levels of 2000, 1800, 1600, 1400, 1200, $800,600,500,400,300,200,150,100$, and 50, 25, $0 \mu \mathrm{mol} \mathrm{m} \mathrm{m}^{-2}$, and a shortest wait time of $120 \mathrm{~s}$ was essential at each irradiance level. Apparent quantum efficiency (AQE), maximum net photosynthetic rate (Amax), dark respiration rate (Rd), light compensation point and light saturation point were estimated by the aid of Photosyn Assistant software, which was designed according to Farquhar model.

\section{Statistical analysis}

The data was subjected to one-way ANOVA followed by Duncan test at 0.05 significance level to compare the means (SPSS 16.0).

\section{RESULTS}

\section{Plant Morphology and Growth}

In comparison with non-AM plants, AMF strains had significant effect on any of the morphological characteristics of maize seedlings (Tab.2). AMF can promote plant height, leaf length and mean leaf width, plant height increased by $23.78 \%$, leaf length and mean leaf width increased by $44.91 \%$ and $39.86 \%$ respectively. Meanwhile, relatively higher shoot and root dry weights were also found in AM seedlings, however, no significant 
difference from root dry weight appeared between

AM and non-AM seedlings.

Tab.2.Plant height, leaf length, mean leaf width and dry weight of shoot and root of maize plants inoculated(M+) or not (M-) with Glomus. tortuosum

\begin{tabular}{llllll}
\hline Inoculation & $\begin{array}{l}\text { Plant height } \\
(\mathrm{cm})\end{array}$ & $\begin{array}{l}\text { Leaf length } \\
(\mathrm{cm})\end{array}$ & $\begin{array}{l}\text { Mean leaf width } \\
(\mathrm{cm})\end{array}$ & & \multicolumn{2}{l}{$\begin{array}{l}\text { Dry weight } \\
(\mathrm{g} / \text { plant })\end{array}$} \\
\cline { 4 - 6 } & & & Shoot & Root \\
\hline M+ & $73.4 \mathrm{a}$ & $48.4 \mathrm{a}$ & $2.07 \mathrm{a}$ & $1.75 \mathrm{a}$ & $0.39 \mathrm{a}$ \\
$\mathrm{M}-$ & $59.3 \mathrm{~b}$ & $33.4 \mathrm{~b}$ & $1.48 \mathrm{~b}$ & $0.88 \mathrm{~b}$ & $0.33 \mathrm{a}$ \\
\hline
\end{tabular}

\section{Osmotic adjustment}

Soluble sugar, soluble protein and proline are important osmotic adjustment substances ${ }^{38}$, whose concentrations were shown in Fig.1. The changes revealed that patterns of soluble sugars were consistent with protein. Compared with non-AM seedlings, soluble sugar and protein concentrations in $\mathrm{AM}$ ones increased by 1.63 and 1.11 times, respectively. However, opposite changes appeared in proline, whose concentration significantly decreased by $35.60 \%$ in AM seedlings under the same conditions.
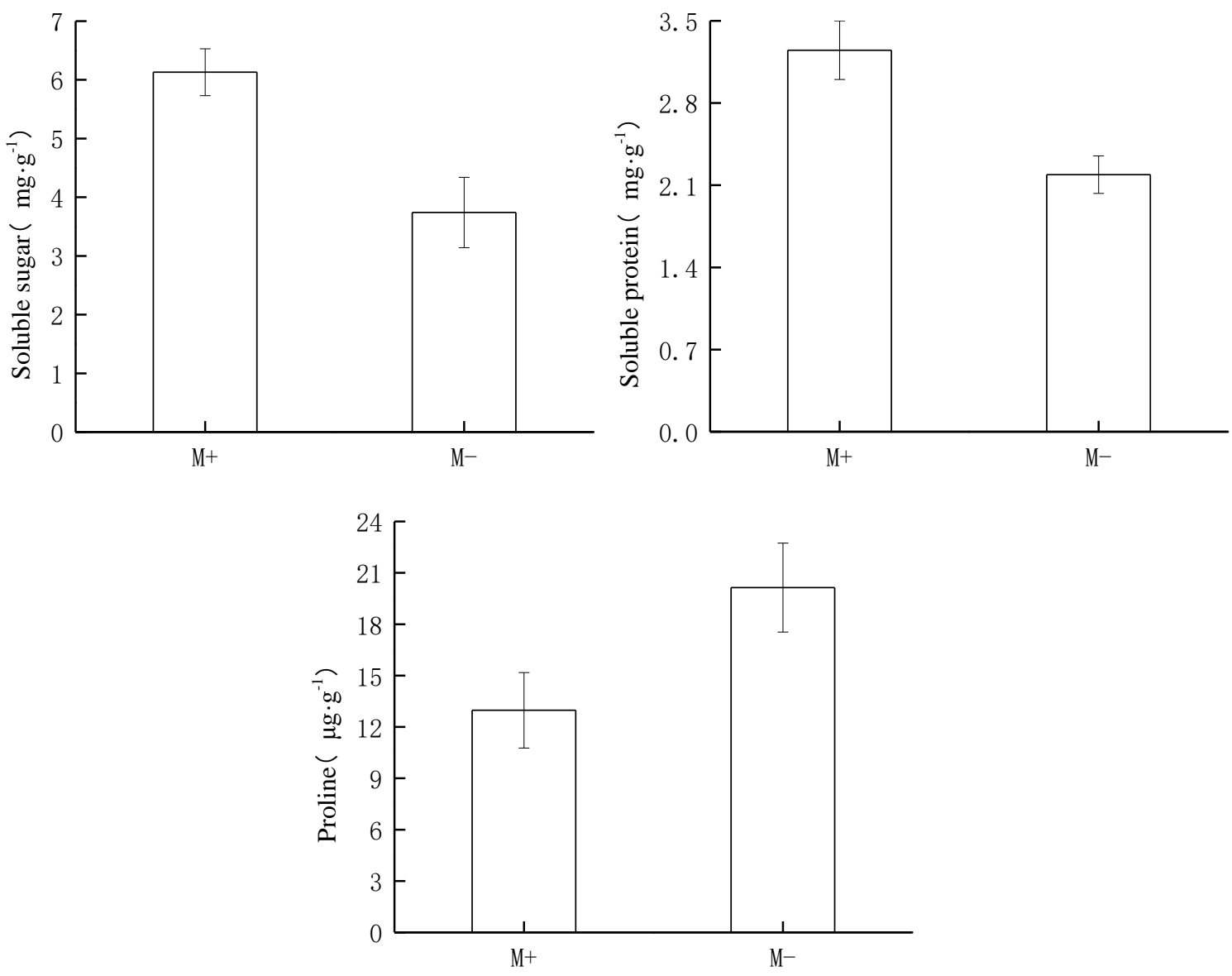

Fig.1.Soluble sugar, soluble protein andprolineconcentrations of maize plants inoculated( $\left(\mathrm{M}^{+}\right)$or not $\left(\mathrm{M}^{-}\right)$with Glomus.tortuosum

\section{Chlorophyll fluorescence}

$F_{o}, F_{m}$ and $F_{v}$, which are important chlorophyll parameters, can reflect a series of adaptive adjusting processes in photosynthetic apparatus. AMF enhanced $F_{m}$ and $F_{v}$ value significantly (Fig.2), however, it reduced $F_{o}$ value in our study. $F_{v} / F_{m}$ and $F_{v} / F_{o}$ are usually used to measure conversion efficiency of primary light energy of PSII and potential PSII activity. In contrast with non-AM maize plants, both $F_{v} / F_{m}$ and $F_{v} / F_{o}$ smoothly increased after inoculating 
Effects of mycorrhizal on osmotic adjustment

with AMF, which was caused mainly by a sharp
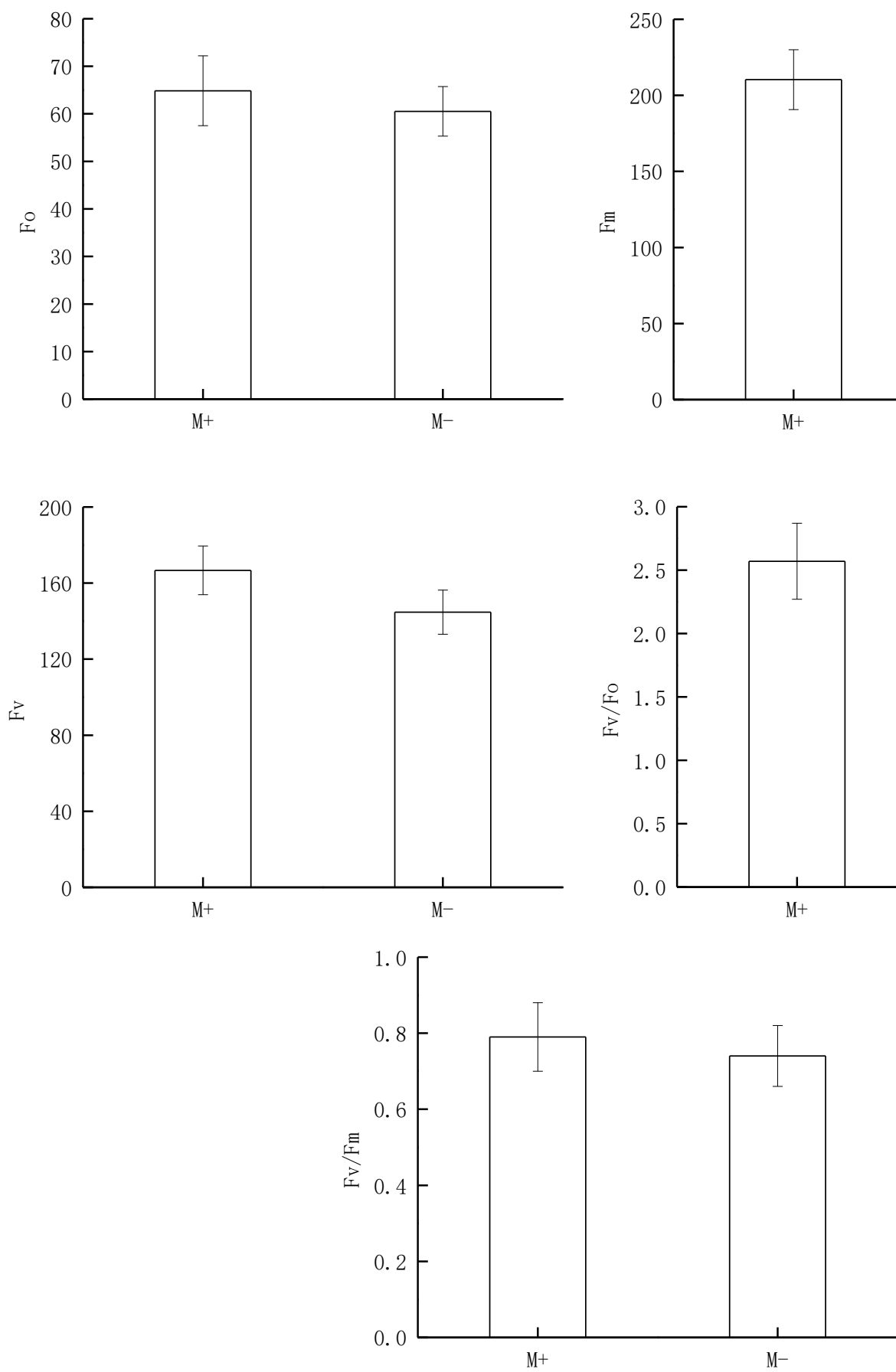

increase in $F_{v}$ value.
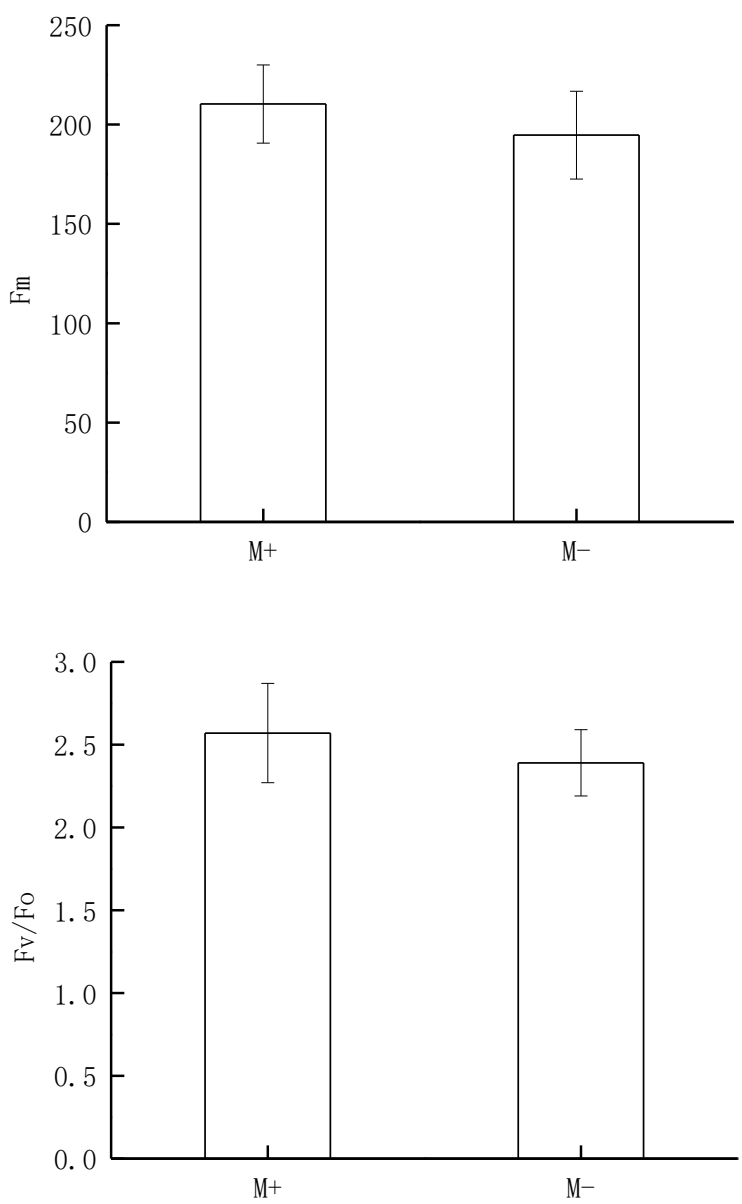

Fig.2. $\mathrm{F}_{\mathrm{o}}, \mathrm{F}_{\mathrm{m}}, \mathrm{F}_{\mathrm{v}}, \mathrm{F}_{\mathrm{v}} / \mathrm{F}_{\mathrm{m}}$ and $\mathrm{F}_{\mathrm{v}} / \mathrm{F}_{\mathrm{o}}$ of maize plants inoculated $(\mathrm{M}+)$ or not $\left(\mathrm{M}^{-}\right)$with Glomus. tortuosum

\section{Photosynthetic parameters}

Photosynthesis is the main factor affecting maize growth, which can be evaluated directly through measurement of photosynthetic parameters. Similar changing trends were found in light response curve of maize in both treatments (Fig.
3). When photosynthetically active radiation (PAR) was in the range from 0 to $2000 \mu \mathrm{mol} / \mathrm{m}^{2} \cdot \mathrm{s}$, net photosynthetic rate $(\mathrm{Pn})$ would increase along with the increase of PAR, and Pn of AM seedlings was higher than the contrast remarkably. AQE represents the efficiency of light utilization, AQE 
increased by $5.56 \%$ after inoculated with AMF (Tab.3). Amax net photosynthetic rate increased by $8.70 \%$ after inoculated with AMF. Rd reduced by $26.46 \%$ after inoculated with AMF. Light compensation point is an important symbol for utilizing weak light, the lower light compensation point, the stronger light utilizing capacity. Light compensation point reduced by $54.34 \%$ after AMF inoculation, and light saturation point decreased by 25.66\% after AMF inoculation.

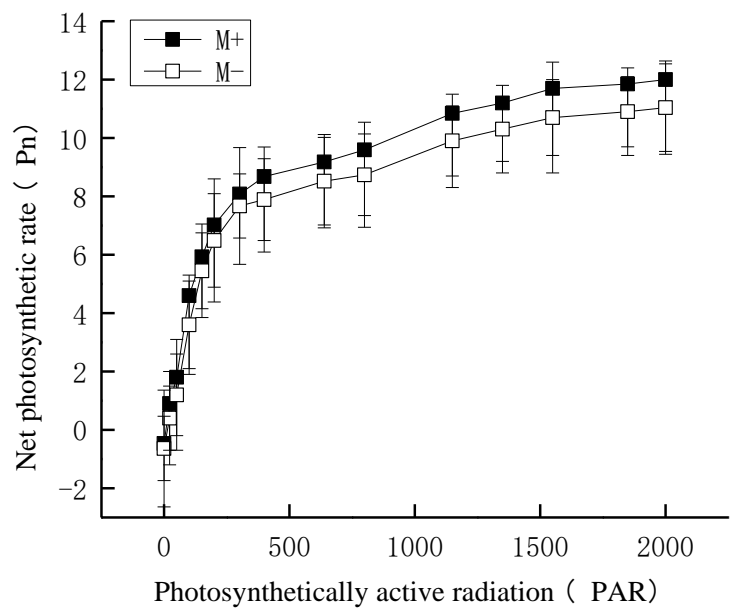

Fig.3. Light response curve of maize plants inoculated $(\mathrm{M}+)$ or not $\left(\mathrm{M}^{-}\right)$with Glomus. tortuosum

Tab.3.Amax, Rd, AQE,Light saturation and Light compensationof maize plants inoculated(M+) or not $(\mathrm{M}-)$ with Glomus.tortuosum

\begin{tabular}{llllll}
\hline Inoculation & Amax & Rd & AQE & Light saturation & Light compensation \\
\hline M+ & $12.30 \mathrm{a}$ & $0.467 \mathrm{~b}$ & $0.038 \mathrm{a}$ & $776 \mathrm{a}$ & $8 \mathrm{~b}$ \\
$\mathrm{M}-$ & $11.31 \mathrm{~b}$ & $0.635 \mathrm{a}$ & $0.036 \mathrm{a}$ & $736 \mathrm{~b}$ & $16 \mathrm{a}$ \\
\hline
\end{tabular}

\section{DISCUSSION}

AMF is able to colonize root system, and result in various changes closely related to physio-ecology of the plant ${ }^{39}$. It was found that plant height, leaf length, and mean leaf width in maize seedlings all dramatically increased when colonized with Glomus. tortuosum. This is due to the regulation on primary metabolism and acquisition material energy and information from photosynthesis. And the favourable impact of AMF on the maize biomass was also observed in present experiment. Biomass can reflect net photosynthetic capacity directly in plant, and also is intuitive index which can indicate AMF effect. Various stimulus matters could produce in the course of formation of AM symbiosis, then stimulate root development. Furthermore, external hyphae can promote absorption of nitrogen and phosphorus nutrition from outside of rhizosphere through the expansion of absorption area in host plants. Which increase nitrogen and phosphorus nutrition contents in plants, and improve nutrition condition, then promote dry matter accumulation.
Osmotic adjustments play an important part in protecting plant from being hurt under abiotic stress condition through accumulation of small, soluble, and organic molecules, which include soluble sugar, soluble protein and proline. There were higher content of soluble sugar and protein occurred in the leaves of AM plants compare with non-AM plants. Protein buildup might be closely related to the enhancement of RuBPcase activities, and accumulated soluble sugar could take effect on protecting key metabolic enzymes through synthesizing small organic molecule ${ }^{26}$. Meanwhile, some absorbed soluble sugar from the surrounding environment could be transformed into storage compounds after inoculating with AMF. It suggested that AMF could increase osmotic adjustments ability, which was a kind of efficient self-protection mechanism. Proline is also a kind of important osmotic adjustment substance, on the one hand, it can maintain osmotic equilibrium of protoplasts and environment, and prevent loss of water. On the other hand, proline can protect membrane structural integrity by scavenging hydroxyl radical ${ }^{40-42}$. There is 
relatively low proline content in AM plants in our study, maybe, it is unnecessary to synthesize more proline because of slight injury.

Photosynthetic characters differ significantly between AM and non-AM plants, and chlorophyll fluorescence has proved to be effective tool for evaluating photosynthetic performance ${ }^{43} \cdot F_{v} / F_{m}$ and $F_{v} / F_{o}$ are two imperative parameters for indication of photochemical reaction. According to the results of experiments, $F_{v} / F_{m}$ increases by AMF. AMF plays a role in $\mathrm{F}_{\mathrm{v}} / \mathrm{F}_{\mathrm{m}}$ increase by improving plants nutritional status and activating mediated genes ${ }^{44}$, and the changes of $F_{v} / F_{m}$ in $A M$ plants might relate to sink stimulation of $\mathrm{AM}$ symbioses ${ }^{45}$. In contrast to $F_{v} / F_{m}, F_{v} / F_{o}$ can provide more valuable information on maize photosynthesis, and $F_{v} / F_{o}$ has similar trend with $\mathrm{F}_{\mathrm{v}} / \mathrm{F}_{\mathrm{m}}$. This implied that $\mathrm{AM}$ plants had higher efficiency of excitation energy capture by open PSII centers on comparison with non-AM plants. Higher $F_{m}$ and $F_{v}$ were detected in $\mathrm{AM}$ plants than corresponding non-AM ones, it suggested that AM symbioses could improve reaction center activity and electron transport rate of maize plants.

Compared with non-AM seedlings, $\mathrm{Rd}$ was significantly lower in AM plants, it indicated that AMF can slow down the speed of product consumption, because mycelium network around mycorrhiza can enlarge absorption area and reduce resistance of liquid flow between soil and plant ${ }^{46}$, furthermore, it can reduce energy needed by root because of absorption of soil nutrient and water. Amax net photosynthetic rate increased after inoculating with AMF, the main factor is that AMF can secrete some special enzymes and accelerate mineral absorption ${ }^{47}$, it is central to meet the needs for maize photosynthesis, thereby cause detectable increase in photosynthetic efficiency. Besides, another major cause was that improved nutritional status can lead to the enlargement of leaf muscularization and the increase of chlorophyll content ${ }^{48}$, it would make further efforts to strengthen light-capturing ability. Moreover, it was also confirmed that AMF enhanced stoma conduction, it was conducive to increase photosynthetic rate ${ }^{49}$. AM seedlings had significantly higher light compensation point and apparent quantum efficiency, but lower light saturation point than corresponding non-AM seedlings, it indicated that AMF enhanced ability of light energy utilization and adaptation to strong light $^{50}$.

\section{CONCLUSION}

It could be concluded from this study that application of AMF improve osmotic adjustment functions to avoid excessive dehydration through the accumulation of soluble sugar and protein in maize. It was also discovered that AM colonization might boost up photosynthesis characters in maize plant by raising light use efficiency and ability to light adaptation. However, AMF might cause complex physiological and biochemical changes associated with maize yield, therefore, it is essential to do further research on the effect of AMF on produce of photosynthate, assimilating translocation and distribution by way of understanding their part in metabolic physiology of maize.

\section{ACKNOWLEDGMENTS}

This research was supported by National Natural Science Foundation of China (41301314, 41471425 and 41301082).

\section{REFERENCES}

1. Yang HS, Yuan YG, Zhang Q, Tang JJ, Liu Y, Chen $\mathrm{X}$. Changes in soil organic carbon, total nitrogen, and abundance of arbuscular mycorrhizal fungi along a large-scale aridity gradient. Catena. 2011; 87: 70-77.

2. Smith SE, Read DJ. Mycorrhizal symbiosis. San Diego:Academic Press; 2008.

3.Liu AR, Chen SC, Wang MM, Liu DL, Chang R, Wang ZH, Lin XM, Bai B, Ahammed GJ. Arbuscular mycorrhizal fungus alleviates chilling stress by boosting redox poise and antioxidant potential of tomato seedlings. J plant growth Regu. 2015;35:109120 .

4. Evelin H, Giri B, Kapoor R. Contribution of Glomusintraradices inoculation to nutrient acquisition and mitigation of ionic imbalance in $\mathrm{NaCl}$-stressed Trigonellafoenum-graecum. Mycorrhiza. 2012;22:203-217.

5. Kapoor R, Evelin H, Mathur P, Giri B. Arbuscular mycorrhiza: Approaches for abiotic stress tolerance in crop plants for sustainable agriculture. In: Tuteja $\mathrm{N}$ and Gill SS (eds) Plant acclimation to environmental stress. LLC:Springer; 2013.

6. Latef AAHA, Cheng C. Arbuscular mycorrhizal influence on growth, photosynthetic pigments, osmotic adjustment and oxidative stress in tomato plants subjected to low temperature stress. ActaPhysiol Plant. 2011;33:1217-1225.

7. Bearden B, Petersen L. Influence of arbuscular mycorrhizal fungi on soil structure and aggregate 
stability of a vertisol. Plant. Soil. 2000; 218:173-183.

8. Asghari HR, Chittleborough DJ, Smith FA, Smith SE. Influence of arbuscular mycorrhizal (AM) symbiosis on phosphorus leaching through soil cores. Plant. Soil. 2005;275:181-193.

9. Manchanda G, Garg N. Alleviation of salt-induced ionic, osmotic and oxidative stresses in Cajanuscajan nodules by AM inoculation. Plant Biosyst. 2011;145:88-97.

10. MiransariM. Use of microbes for the alleviation of soil stresses. Berlin:Springer; 2014.

11. Yooyongwech S, Samphumphuang T, Tisarum R, Theerawitaya C, Cha-um S. Arbuscular mycorrhizal fungi (AMF) improved water deficit tolerancein two different sweet potato genotypes involves osmotic adjustments via soluble sugar and free proline. SciHortic-Amsterdam. 2016; 198: 107117.

12. Evelin H, Giri B, Kapoor R. Ultrastructural evidence for AMF mediated salt stress mitigation in Trigonellafoenum-gr aecum. Mycorrhiza. 2013;23:7186.

13. Zhu XC, Song FB, Xu HW.Arbuscular mycorrhizae improve low temperature stress in maize via alterations in host water status and photosynthesis. Plant Soil. 2010; 331:129-137.

14. Hajiboland R, Aliasgharzadeh N, Laiegh SF, Poschenreider C. Colonization with arbuscular mycorrhizal fungi improves salinity tolerance of tomato (Solanumlycopersicum L.) plants. Plant. Soil. 2010;331:313-327.

15. Xie X, Weng B, Cai B, Dong Y, Yan C. Effects of arbuscular mycorrhizal inoculation and phosphorus supply on the growth and nutrient uptake of Kandeliaobovata (Sheue, Liu \& Yong) seedlings in autoclaved soil. App Soil Eco. 2014;75:162-171.

16. Babita M, Maheswari M, Rao LM, Shanker AK, Rao DG. Osmotic adjustment, drought tolerance and yield in castor (Ricinuscommunis L.)hybrids. Environ. Exp Bot. 2010; 69:243-249.

17. Abdel Latef AA, Chaoxing H. Effect of arbuscular mycorrhizal fungi on growth, mineral nutrition, antioxidant enzymes activity and fruit yield of tomato grown under salinity stress. SciHortic. 2011;127:228-233.

18. Abdel Latef AA, Chaoxing H. Does the inoculation with Glomusmosseae improve salt tolerance in pepper plants?. J Plant Growth Regulat. 2014;doi: 10.1007/s00344-014-9414-4.

19. Sheng $\mathrm{M}$, Tang $\mathrm{M}$, Zhang $\mathrm{F}$, Huang $\mathrm{Y}$. Influence of arbuscular mycorrhiza on organic solutes in maize leaves under salt stress. Mycorrhiza. 2011;21:423-430.

20. Talaat NB, Shawky BT. Protective effects of arbuscular mycorrhizal fungi on wheat (Triticumaestivum L.) plants exposed to salinity. Environ Exp Bot. 2014;98:20-31.

21. Hameed A, Dilfuza E, Abd-Allah EF, Hashem
A, Kumar A, Ahmad P. Salinity stress and arbuscular mycorrhizal symbiosis in Plants. In: Miransari M (ed) Use of microbes for the alleviation of soil stresses.New York: Springer; 2014.

22. Aldesuquy HS, Baka ZA, Mickky BM. Wheat can acclimate to seawater by pretreatment with kinetin and spermine through osmotic adjustment and solutes allocation. J. Stress PhysiolBiochem. 2013;9:181-198.

23. Boussadia O, Bchir A, Steppe K, Labeke MV, Lemeur R, Braham M. Active and passive osmotic adjustment in olive tree leaves during drought stress. EurSci J. 2013;9: 423-439.

24. Zhou W, Sun QJ, Zhang CF, Yuan YZ, Zhang $\mathrm{J}$, Lu BB. Effect of salt stress on ammonium assimilation enzymes of the roots of rice (Oryza sativa) cultivars differing in salinity resistance. ActaBota Sin. 2004; 46:921-927.

25. Porcel R, Ruiz-Lozano JM. Arbuscular mycorrhizal influence on leaf water potential, solute accumulation and oxidative stress in soybean plants subjected to drought stress. J.Exp Bot. 2004;55:17431750.

26. Wu_QS, Xia RX. Arbuscular mycorrhizal fungi influence growth, osmotic adjustment and photosynthesis of citrus under well-watered and water stress conditions. J. Plant Physiol. 2006; 163: 417425.

27. Tubeileh A, Groleau-Renaud V, Plantureux S, Guckert A. Effect of soil compaction on photosynthesis and carbon partitioning within a maize-soil system. Soil TillRes. 2003;71:151-161.

28. Zhu XC, Song FB, Liu SQ, Liu TD.Effects of arbuscular mycorrhizal fungus on photosynthesis and water status of maize under high temperature stress. Plant Soil. 2011;346:189-199.

29. Ma P, Bai TH, Wang XQ, Ma FW. Effects of light intensity on photosynthesis and photoprotective mechanisms in apple under progressivedrought. J IntegrAgr. 2015; 14:1755-1766.

30. Catoni R, Gratani L. Variations in leaf respiration and photosynthesis ratio in response to air temperature and water availability among Mediterranean evergreen species. J Arid Environ, 2014;102: 82-88.

31. He Y, Yang J, Zhu B, Zhu ZJ. Low Root Zone Temperature Exacerbates the Ion Imbalance and Photosynthesis Inhibition and Induces Antioxidant Responses in Tomato Plants Under Salinity. J IntegrAgr. 2014;13:89-99.

32. Wei SS, Wang XY, Shi DY, Li YH, Zhang JW, Liu P, Zhao B, Dong ST. The mechanisms of low nitrogen induced weakened photosynthesis in summer maize (Zea mays L.) under field conditions. Plant PhysiolBioch. 2016;105:118-128.

33. Fletcher AL, Moot DJ, Stone PJ. Radiation use efficiency and leaf photosynthesis of sweet corn in 
Effects of mycorrhizal on osmotic adjustment

response to phosphorus in a cool temperate environment. Eur J Agrono. 2008;29: 88-93.

34. Zhu XC, Song FB, Liu FL. Altered amino acid profile of arbuscular mycorrhizal maize plants under low temperature stress. J Plant Nutr Soil Sci. 2016; 179: 186-189.

35. Liu ZL, Li YJ, Ma LNH, Wei C, Zhang JF, He XY, Tian CJ. Coordinated regulation of arbuscular mycorrhizal fungi and soybean MAPK pathway genes improved mycorrhizal soybean drought tolerance. Mol Plant Microbe In. 2014;28:408-419.

36. Zhang ZL, Qu WJ. Experimental guidance of plant physiology. Beijing: High Education Press; 2003.

37. Bradford MM. Arapid and sensitive method for the quantitation of microgram quantities of proteinutilizing the principle of protein-dyebinding. Anal.Biochem. 1976;72: 248-54.

38. Xu HW, Lu Y, Xie ZM, Song FB, Changes in nitrogen metabolism and antioxidant enzyme activities of maize tassel in black soils region of northeast China. Front Plant Sci. 2014;10:1-6.

39. He Y, Li YQ, Li X. The research of cold stress on three revetment plants. J Agr Sci. 2013; 5: 102106.

40. Chen SC, Jin WJ, Liu AR, Zhang SJ, Liu DL, Wang FH, Lin XM, He CX. Arbuscular mycorrhizal fungi (AMF) increase growth and secondary metabolism in cucumber subjected to low temperature stress. SciHortic. 2013;160:222-229.

41. Kishor PBK, Sangama S, Amrutha RN, Laxmi PS, Naidu KR, Rao KS. Regulation of proline biosynthesis degradation, uptake and transport in higher plants: its implications in plant growth and abiotic stress tolerance. Curr Sci. 2005;88:424-438.

42. Sharma SS, Dietz KJ. The significance of amino acids and amino-acid derived molecules in plant responses and adaptation to heavy metal stress. J Exp Bot. 2006;57:711-726.

43. Oyetunji OJ, Ekanayake IJ, Osonubi O. Chlorophyll fluorescence analysis for assessing water deficit and arbuscular mycorrhizal fungi (AMF) inoculation in Cassava (ManihotesculentaCrantz). Adv. Biol Res. 2007;1:108-117.

44. Shool A, Shamshiri MH. Effect of arbuscular mycorrhizal fungi and Pseudomonas fluorescence on chlorophyll fluorescence and photosynthetic pigments of pistachio seedlings (Pistaciavera $c v$. Qazvini) under four water regimes. Eur J. Exp Biol. 2014; 4:246-252.

45. Zhu XC, Xu HW, Song FB. Influence of arbuscular mycorrhiza on lipid peroxidation and antioxidant enzyme activity of maize plants under temperature stress.Mycorrhiza. 2010;20: 325-332.

46. Kong J, Pei ZP, Du M, Sun G, Zhang X.

Effects of arbuscular mycorrhizal fungi on

the drought resistance of the mining area repair plant Sainfoin. Int $\mathbf{J}$ Min Sci Technol. 2014;24:485-489

47. Ye SP, Yang YJ, Xin GR, Wang YT, Ruan L, Ye GR. Studies of the Italian ryegrass-rice rotation system in southern China: Arbuscular mycorrhizal symbiosis affects soil microorganisms and enzyme activities in the Lolium mutiflorum L. rhizosphere. Appl Soil Ecol. 2015;90:26-34.

48. Tsimilli-Michael M, Eggenberg P, Biro B, Köves-Pechy K, Vörös I, Strasser RJ. Synergistic and antagonistic effects of arbuscular mycorrhizal fungi and Azospirillum and Rhizobium nitrogen-fixers on the photosynthetic activity of alfalfa, probed by the polyphasic chlorophyll a fluorescence transient O-J-IP. Appl Soil Ecol. 2000;15:169-182.

49. Augé RM. Water relations, drought and vesicular-arbuscular symbiosis.Mycorrhiza. 2001;11: 3-42.

50. RozpądekP, WężowiczK, NosekM, WażnyR,T okarz K, LembiczM, MiszalskiZ, TurnauK.The fungal endophyte Epichloëtyphina improves photosynthesis efficiency of its host orchard grass (Dactylisglomerata).Planta. 2015;242:1025-1035.

Received: June 22, 2016; Accepted: June 22, 2016 